3

4 aa Department of Anthropology, Yale University, New Haven, CT, 06511, USA, $5 \quad$ jessica.thompson@yale.edu

$6{ }^{\mathrm{b}}$ Department of Archaeology, Conservation and History, University of Oslo, Oslo, N-0315,

7 Norway, david.wright@iakh.uio.no

8 'State Key Laboratory of Loess and Quaternary Geology, Institute of Earth Environment, 9 Chinese Academy of Sciences, Xi'an, 710061, China

\section{The emergence and intensification of early hunter-gatherer niche construction}

Jessica C. Thompson $^{\mathrm{a}^{*}}$, David K. Wright ${ }^{\mathrm{b}, \mathrm{c}}$, and Sarah J. Ivory ${ }^{\mathrm{d}}$

${ }^{\mathrm{d}}$ Department of Geosciences and Earth and Environmental Sciences Institute, Pennsylvania State University, University Park, PA 16802, USA, sarah ivory@psu.edu

*Corresponding author

\section{Author Biographies:}

Jessica Thompson is Assistant Professor of Anthropology at Yale University. David Wright is Professor of Archaeometry at the University of Oslo. Sarah Ivory is Assistant Professor of Geosciences at Pennsylvania State University. They began to link their ideas between archaeology and paleoenvironments in Malawi in 2016.

Running Title: Niche construction in early hunter-gatherers 


\section{Glossary:}

Tipping point: A threshold leading to a regime shift.

Regime shift: A change to a new condition or state in which controls and feedbacks that regulate

27 the system have been altered.

Subsistence intensification: Modification of behavior or technology to obtain more net product from a given subsistence resource.

Behaviorally Mediated Trophic Cascades: Changes in ecological systems that occur when prey adjust their behavior in response to predators. Complimentary adjustments in microbial, plant and/or animal life beyond the direct predator-prey dynamic can ripple through space and time.

N-driven (population size) systems: A system in which the main impacts to a system's ecology can be measured through direct population reduction of prey by predators.

$\boldsymbol{\mu}$-driven (fear) systems: A system in which the main impacts to a system's ecology can be measured through prey avoidance of predation risk.

Turnover: A supplanting of one trophic complex with another following a regime shift. Intertropical Convergence Zone: Earth's zone of atmospheric pressure convergence that migrates annually across the tropical latitudes in response to solar-heat flux.

Climatic antiphasing: Opposing climate conditions in different geographic regions that are a non-linear response to global or mesoscale forcing mechanisms. 
58 59 60

\section{Abstract}

Hunter-gatherers, especially Pleistocene examples, are not well-represented in archaeological studies of niche construction. However, as the role of humans in shaping environments over long time scales becomes increasingly apparent, it is critical to develop archaeological proxies and testable hypotheses about early hunter-gatherer impacts. Modern foragers engage in niche constructive behaviors aimed at maintaining or increasing the productivity of their environments, and these may have had significant ecological consequences over later human evolution. In some cases, they may also represent behaviors unique to modern Homo sapiens. Archaeological and paleoenvironmental data show that African hunter-gatherers were niche constructors in diverse environments, which have legacies in how ecosystems function today. These can be conceptualized as behaviorally mediated trophic cascades, and tested using archaeological and paleoenvironmental proxies. Thus, large-scale niche construction behavior is possible to identify at deeper time scales, and may be key to understanding the emergence of modern humans.

Keywords: Middle Stone Age; Burning; Environmental Impacts; Foragers; Pleistocene; modern human 


\section{INTRODUCTION}

Modern humans impact and alter their environments in ways that profoundly affect themselves and other organisms. Niche construction is a concept defined as the process by which organisms actively modify their own and each other's evolutionary niches ${ }^{1}$. Biologists, psychologists, and - more slowly - anthropologists have begun to appreciate its clear applicability as they seek to understand the long-term impacts of human-environment interactions ${ }^{2-6}$. One important question then becomes when, and by what processes, modern humans transitioned from a species where fitness was largely controlled by environment to one that primarily structures its own selective environment. This demands critical assessment of how these behaviors and their impacts can be detected, and with what fidelity they can be interpreted, at different points in human prehistory.

The 'Paleoanthropocene' refers to a conceptual period of anthropogenic impacts that predate the Industrial Revolution ${ }^{7}$. Similar to Glikson's ${ }^{8}$ proposed division of the Anthropocene into an 'Early', 'Middle', and 'Late', it is a useful way to imagine the evolution of human impacts over a long period, rather than a sharp division marked by a 'Golden Spike'. The archaeological record is full of examples in which humans alter the ecological balance within their niche, but these become more controversial to identify as one moves back in time ${ }^{9}$. As the continent where human evolution can be traced to its roots, Africa is likely to possess the longest records of anthropogenic impacts on ecological systems. However, it may also be the place where such impacts are most difficult to resolve. This is because the very long co-evolution of hominins and other organisms does not provide an obvious 'before' and 'after' time for human presence. 
Before the global spread of modern humans between ca. 100 - 50 thousand years ago (ka), the primary proxies for hominin impacts have been changes in animal community structure. For example, declines in carnivore diversity correspond to an increase in hominin brain size over the last ca. 4 million years, and may be linked to encroachment into more carnivorous niches ${ }^{10}$. In contrast, however, megaherbivore declines do not appear to be related to changes in the hominin lineage ${ }^{11}$. Later in time, there has been substantial controversy over the role of humans in the extinction of megafaunal species ${ }^{12}$. This leaves open the question of when humans and human ancestors began to implement niche-constructing behaviors at a scale that accelerated their impacts relative to other ecosystem constituents. Because one of the most prominent behaviors unique to hominins is the control of fire, tracking its use over more than a million years has been proposed as a way of tracking anthropogenic modifications ${ }^{13}$. This comes with the practical problems of identifying control of fire on site, and then extrapolating that control to broader off-site uses likely to have substantial environmental consequences.

Here, we examine the evidence that early modern human niche construction had largescale impacts on our species and other organisms long before the advent of more obvious transformations such as food production ${ }^{14}$. From this, we suggest that the emergence of our particular scale of niche construction represented a threshold-crossing event in both our own evolution and that of the ecosystems we inhabit. As with other eco-evolutionary feedbacks ${ }^{15}$, this adaptation was scaffolded by long histories of organism-environment co-evolution ${ }^{16}$. Uniquely with humans, the end result has been niche construction of "unrivaled potency" 17. Therefore, if we are to understand the emergence of human behaviors and how they continue to impact ecosystems today, then we must also devote more attention to detailing the course and evolution of early human niche construction. 


\section{NICHE CONSTRUCTION AND THE HUMAN ADAPTATION}

Attempts to understand the origin and pan-global distribution of our species emphasize finding those aspects of our biology and/or behavior that have underpinned our success. Homo sapiens occupy a larger range of habitats than any mammal species, and this global dispersion occurred when all humans were hunter-gatherers. Thus, we must understand the emergence of key adaptations under this form of subsistence. An interconnected web of technological, social, and cognitive aspects of human lifeways have resulted in an organism that is behaviorally flexible, and can draw on inter-generational and between-group knowledge systems to facilitate a skilled extractive foraging adaptation ${ }^{18-21}$. The interdependency of these relationships has led some researchers to conclude that culture is the human niche ${ }^{22,23}$, and that we should therefore pay particularly close attention to co-evolution of both genes and culture ${ }^{24,25}$. Understanding the roles of natural selection, niche construction, and culture therefore matters substantially in explaining the evolution of both our own species and the other organisms with which we share ecosystems ${ }^{26}$.

\section{In placing any investigation of the emergence of modern humans within the}

\section{framework of niche construction theory (NCT), however, there remains the pragmatic} problem of which past human behaviors are actually archaeologically accessible. The selective environments within the social and subsistence realms are to an extent visible through analyses of material culture and food remains. However, the resolution of this record coarsens going back in time, and preservation becomes a greater obstacle. This tends to telescope the problem, so that human niche construction is most frequently discussed in connection with dramatic and well-documented recent changes wrought by the advent of food production ${ }^{4,14,27,28}$. Compounding the problem of identifying earlier modifications is the fact that ecological 
conditions cannot be tidily separated into distinct time-slices; they are always at least partially the legacy of past conditions. As humans began to take a more central role in transforming their ecologies, these legacy effects of their previous niche-constructing behaviors became more influential on their later ones.

Although niche construction is not unique to modern Homo sapiens, a defining feature of our emergence has been our unprecedented ability to transform the ecology of the world around us. This transition to ecological dominance represents a fundamental change in how rapidly and decisively human populations can facilitate ecological regime shifts, in which there is a demonstrably different change in state, often underpinned by changes in controls that regulate a system ${ }^{29}$. Tipping points are a useful concept for understanding anthropogenically induced regime shifts in the past not because they represent a simple "on/off" switch on human behavior $^{30}$, but because they may be more visible over long time scales and within the coarse resolution of the Pleistocene paleoecological and archaeological records. Depending on the scale of analysis, accumulations of impacts may not result in clear tipping points, but sometimes tipping points can be reached rapidly and can be detected ${ }^{31}$. However, from a practical perspective, regime shifts facilitate our ability to 'see' changes in past systems by contrasting how they have changed through time. Tipping points can represent identifiable thresholds at which humansentered a new balance with their ecosystems, and where the previous state cannot be reconstituted without significant effort. Conceptually, once an ecological system has crossed a tipping point, the initial assembly of components in the new state, any underlying controls, and their proxy components in the paleoenvironmental and archaeological records, is rapid, but slows into an equilibrium or semi-equilibrium. However, new pressures (e.g., climate change, extinction events, changes in predation, changes in the influence of one component) can push the 
152

153

154

155

156

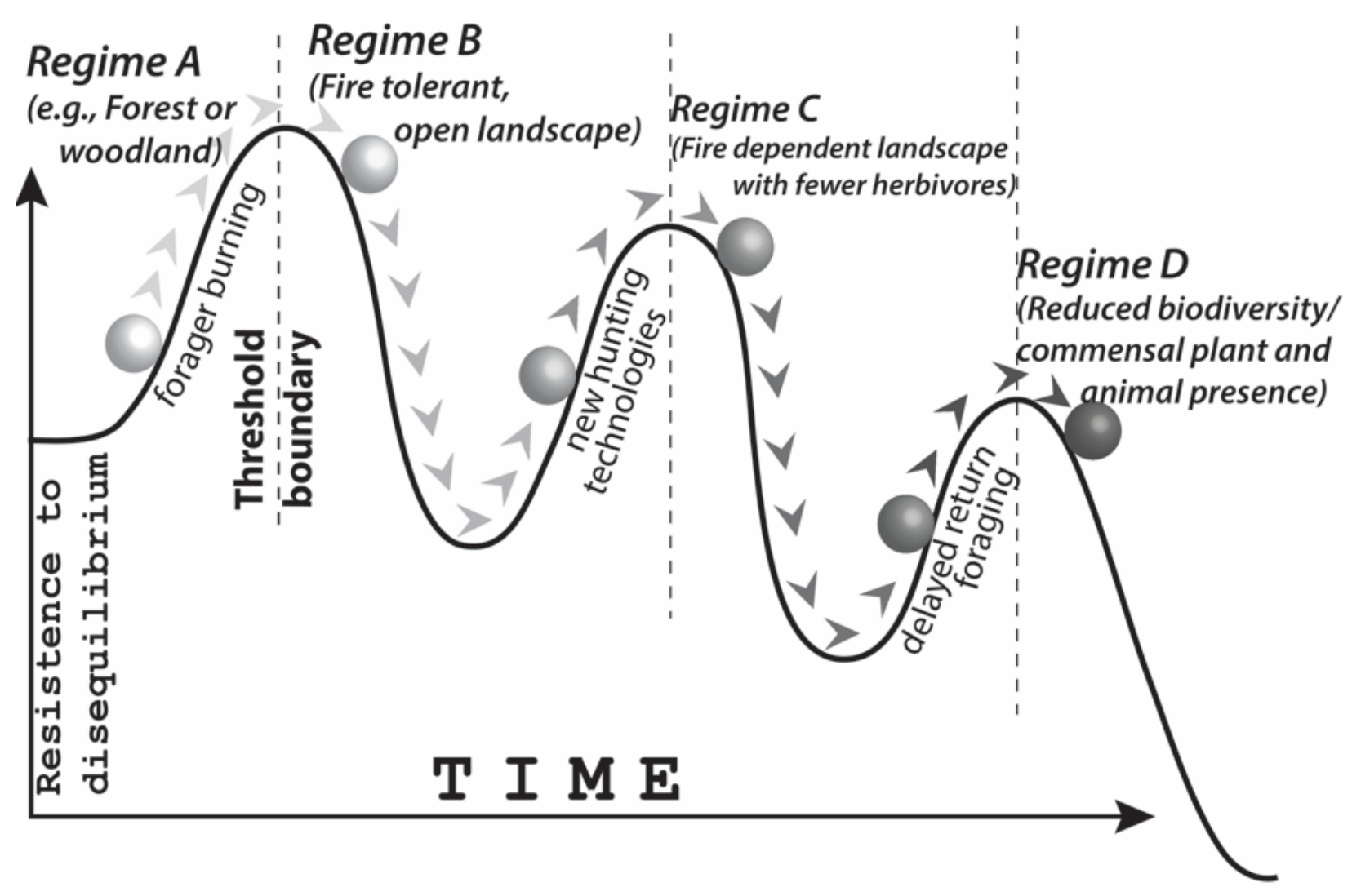

system toward a new state of disequilibrium and closer to a new regime (Fig. 1). Ecological or even social tipping points are not to be conflated with narratives of 'revolutions' in human behavior, because they can occur after a long accumulation of impacts, and inherit legacies of previous systems. An example again is control of fire, and the significant changes it wrought on both social and ecological systems as they changed together ${ }^{32}$.

Figure 1. Model of ecosystem threshold crossing. As ecosystems cross multiple tipping points, they inherit accumulated effects of the evolution of the system over long time periods. The x-axis is time and the y-axis is a friction model of resistance of landscapes to change. Impacts are more accumulative when more thresholds are crossed. Therefore, acceleration is more profound on the way down than resistance is on the way up. 
164

165

166

167

168

169

170

171

172

173

174

175

176

177

178

179

180

181

182

183

\section{ENVIRONMENTAL MODIFICATION BY HUNTER-GATHERERS}

We should not expect equivalent behaviors between hunter-gatherers in modern and ancient environments for four reasons: 1) Ecosystems have changed substantially with climate shifts; 2) Modern environments retain legacies of more recent human impacts; 3) Huntergatherers lived across a much wider range of environments than those in which ethnographicallydocumented groups survive; and 4) Ancient environments should also have had an evolving legacy effect from the niche-constructing activities of earlier organisms, including humans. However, observations of strategies used by hunter-gatherers in the present day can be used to build test expectations about what kinds of proxy evidence may be informative about the past ${ }^{33}$. Then, observations from the archaeological and paleoenvironmental records can be used to examine the evidence for such strategies.

The concept of subsistence intensification - the process by which more return is extracted from the same set of resources - is a useful framework for understanding shifts in huntergatherer strategies. It offers insight into how hunter-gatherers deal with changing abundances of resources, how their strategies lead to further changes in both subsistence and other behaviors, and how they can cascade across ecosystems ${ }^{34}$. In the past, population expansion likely had an underlying role in many of these changes, as an arms race between the increasing effectiveness of food acquisition and the need to further improve on those strategies, as increased human carrying capacity then promoted further expansion ${ }^{35}$. The outcome can be substantial environmental impacts.

Forager economies with greater input from delayed-return resources can trigger many of the same effects as food producers in that they foster environmental changes through decreased mobility and increased population growth ${ }^{36}$. More mobile foragers generally utilize larger areas 
187 per unit of extracted food compared to farmers or pastoralists, although in areas with dense 188 patches of resources, the disparity in resource yields is not great ${ }^{37,38}$. Technological and social 189 solutions such as hunting with nets can close the disparity, by artificially increasing the density 190 of resource patches or decreasing the effort required to exploit them ${ }^{39}$. Social environments in 191 which non-related groups interact with each other may also facilitate or exacerbate 192 intensification ${ }^{40}$. Thus, a shift in perspective to an NCT framework brings existing ancient 193 subsistence data into sharper focus as an avenue for understanding fundamental shifts in human194 environment interactions. For example, it may be more useful to examine how changes in diet 195 breadth had recursive impacts on both humans and their ecosystems, rather than simply 196 explaining them as a response to changing environments or population sizes.

198 from foraging, via the management of wild resources prior to their domestication ${ }^{41}$. In some 199 cases, it is also possible to identify structural modifications made by hunter-gatherers to 200 landscapes to drive game ${ }^{27,42}$. However, both cases have limited utility for understanding the 201 evolution of very early human niche construction, because they represent behaviors restricted to 202 specific times and/or places. Here, we highlight fire use as a strategy that is both dramatically 203 transformative of ecosystems and has the potential to be detected deeper in time and more 204 universally across space as it was used to drive game, clear areas, and stimulate resource renewal $205 \quad 43$.

207 resource productivity may have been one of its earliest uses ${ }^{43}$. It is best studied in Australia, 208 where it results in landscapes with diverse successional stages that especially promote 209 acquisition of small game ${ }^{44}$. Notably, the efficacy of fire use in these contexts is dependent on 
210

211

212

213

214

215

216

217

218

previous fire history in a landscape, implying that generational effects would have been important in the emergence of these behaviors. For example, the Martu hunter-gatherers in Australia preferentially occupy areas that have long histories of fire modification, as these have become more productive over time ${ }^{45}$. Because on-site fire use (for cooking, signaling, etc.) is so different from off-site fire use (for resource stimulation), proxies of off-site burning may be more readily discerned in the paleoenvironmental record, such as charcoal from lake cores, rather than the archaeological record. This may be a solution to seeking evidence of this behavior in the past in the form of hearths and terrestrial charcoal features, which will not uniformly preserve.

\section{4. 'SEEING' THE AFRICAN PALEOANTHROPOCENE}

Although hominins have long been niche constructors ${ }^{46}$, material culture changes across the Middle-Late Pleistocene boundary (126 ka) attest to a fundamental shift in the way humans organized themselves and interacted with their environments. Even though chronological coarseness and preservation bias increase over time, the complexion of the material culture record independently changes as one moves forward in time. Direct evidence for social and symbolic behavior becomes increasingly common over the course of the Late Pleistocene, even where taphonomic variables are comparable, suggesting accretionary change across several realms of human behavior ${ }^{47}$. Early examples of complex behaviors such as long-distance trade networks ${ }^{48}$, pigment use ${ }^{49}$, stone-tipped projectile use ${ }^{50}$, and scheduled foraging ${ }^{20}$ are increasingly apparent in the Middle Pleistocene African record between ca. 350 - 150 ka. These began to appear around the same time that the earliest skeletally modern humans have been identified from North Africa ${ }^{51}$. However, it was not until the Late Pleistocene that these initial indicators of an important behavioral adaptation began to make a more systematic appearance ${ }^{52}$. 
We interpret this shift in the archaeological record as reflecting a coalescence of ecologically impactful behaviors, built on social and technological complexity, that amplified during the Middle Pleistocene, and became realized across Africa by the Late Pleistocene ${ }^{8,52-54}$. Because many of the changes in the Late Pleistocene record reflect new hunting technologies ${ }^{50}$, incorporation of novel resources into the diet ${ }^{55}$, complex applications of plant use and pyrotechnology ${ }^{56}$, and expansions into new ecological niches ${ }^{57}$, we should expect associated changes in the dynamics between humans and their environments. Thus, an important area of investigation should be how the impacts of human actions began to take on a new and significant scale in African ecosystems.

Some examples already exist with respect to encroachment into an increasingly diverse dietary niche. This demanded major changes in scheduling of foraging activities, development of inter-group connections, and identity-making ${ }^{20}$. The terrestrial faunal record shows that site use became more intensive, repetitive, and localized over time. In some cases these transformations were subtle; for example, at Rifle Range in Somalia, foragers decreased their emphasis on large, mobile herding mammals across the Pleistocene-Holocene boundary and focused instead on small, territorial antelope ${ }^{58}$. In North Africa, wild caprines (Barbary sheep) were first the target of specialized hunting. By $\sim 8500-7500 \mathrm{BP}$, dung accumulations in caves in the Libyan Sahara suggest they were kept as a delayed-return food that could be exploited as needed ${ }^{59}$. Regions of northern and eastern Africa with early evidence of intensification also show some of the first interactions between hunter-gatherers and pastoralists. The line between the two is blurred, however, because hunter-gatherers had by that point already engaged for several thousand years with the incorporation of delayed return and intensification strategies, which has been argued to have enhanced open landscape formation of vast swaths of northern Africa ${ }^{60}$. These factors 
255 combined may have contributed to the early adoption of pastoralism in this region compared to parts of Africa farther south ${ }^{61}$.

In multiple parts of Late Pleistocene Africa, aquatic resource exploitation speaks to a constructing behaviors, as humans began to invade more fully into ecosystems in a way that demanded substantial changes in human technology and behavior. In central Africa, this may be apparent as early as $\sim 95 \mathrm{ka}$, when barbed bone points (harpoons) occur at Katanda in the modern-day Democratic Republic of Congo ${ }^{55}$. Evidence of much more investment in aquatic resources then appears in a substantial way in both this region and across the Pleistocene-

264 Holocene transition around the Great Lakes Region of East Africa, requiring even more investment in technology and transforming settlement patterns ${ }^{62}$. This implies a legacy effect of millennia of exploitation of these resources. In many cases, intensification anticipated and facilitated later changes to ecological systems that would occur with food production. Thus, food production can be viewed as part of a continuum of niche constructing behaviors that began with Pleistocene hunter-gatherers.

The pan-African pattern of increasing diet breadth and intensification of resources in

271 Pleistocene hunter-gatherers speaks to common factors that shape niche constructing behaviors.

272 These commonalities connect with, rather than conflict with, the predictions of optimal foraging 273 theory ${ }^{63,64}$. As resources become less profitable per unit of time investment, diet breadth should 274 expand to encompass new resources. Recalling that human fitness relies on both biological and 275 cultural factors ${ }^{65}$, major changes in technological needs, acquired skillsets and knowledge, and 276 social organization fundamentally alters the selective environments of humans. Thus, much in 277 the same way that such feedbacks played a role in the development of food production and its 
278 effects on human groups ${ }^{4,63}$, an expansion of diet breadth or intensification may have had a

279 similar effect much earlier in time, with hunter-gatherers. There are significant challenges,

280 however, to identifying examples of intensification in the Pleistocene. Not all sites preserve

281 artifacts or ecofacts that are useful for reconstructing subsistence, and changes in technology and

282 sociality may not always carry over into the types of artifacts that most readily preserve ${ }^{52}$. Other

283 indicators, such as anthropogenic fire used to reconfigure resources across the landscape, may

284 not be expected to preserve at archaeological sites at all. Fire used in this way is one of the most

285 potent tools available to modern humans, yet it is one of the most elusive to identify ${ }^{66}$. We can

286 expand our ability to identify such behaviors through careful attention to off-site proxy records,

287 pairing of archaeological and paleoenvironmental data, and development of hypotheses within a

288 theoretical framework that explicitly addresses the problem of ecological follow-on effects.

\section{5. AN ECOLOGY OF FEAR}

Organisms do not live in isolation, and the introduction or removal of one component can

291 push an ecological system across a threshold that is difficult to reverse. Using the concept of an

292 'ecology of fear', predators structure their environments in two ways: direct prey depletion and

293 altering prey behavior. Behaviorally mediated trophic cascades (BMTCs) may occur if a predator

294 alters the behavior of prey in a way that cascades through the ecosystem. Foraging theory

295 establishes two primary contrasting needs among organisms to ensure survival: food and safety

$296 \quad{ }^{67}$. Species that are typically 'prey' have evolved to elude predation and adopt avoidance

297 strategies in order to maximize their reproductive success. The ecology of fear implies chain

298 reactions in behavior and landscape responses in relation to stealth, vigilance and fear within

299 trophic systems such that both food and safety are maximized ${ }^{68}$. Late Pleistocene humans had 
extraordinary potential to initiate BMTCs as they spread around the globe and into novel environments ${ }^{21}$, rapidly becoming top predators in new ecosystems.

Within the context of the broader landscapes organisms inhabit, there is a continuum between $N$-driven (population size) versus $\mu$-driven (fear) systems ${ }^{68,69}$. In $\mu$-driven systems, the predator reduces the number of prey mainly by fear, driving them out of preferred habitat into suboptimal foraging patches rather than by killing them. This causes prey to aggregate or disperse in specific parts of the landscape, which in turn may lead to nutrient enrichment (through dropping dung) or habitat over-exploitation. In modern African savanna ecosystems, the presence of megaherbivores can change this dynamic by re-establishing nutrient equilibrium in parts of the landscape depopulated by mesoherbivores, which are more prone to predation ${ }^{70}$. Thus, the removal of megafauna or carnivores from a landscape - by direct human hunting, climate, or a combination of these - will make a total ecosystem far more vulnerable to the impacts of apex predators such as humans. BMTCs may also be mediated by other factors such as fire, which alters the distribution and abundance of browse as well as exposure to predation risk $^{71}$. Humans may therefore alter the ecology of fear not only through direct predation on herbivores, but through their use of sophisticated communication and social cooperation, which force prey animals to move into zones in which humans are unable to see or hear one another as effectively. Uniquely, humans possess the power to modify landscapes, including these zones, through controlled fire.

Heretofore, fear-based ecological models have rarely been considered for the evolution of anthropogenic systems. An argument drawn from BMTC theory would posit that there are significant landscape effects within $\mu$-driven ecological systems, and humans are as capable as any another predator to induce cascading ecological influences across them. We argue here that 
323 humans are not only capable, but also exceptional, because of their rapid ability to employ 324 myriad complex behavioral, technological, and cultural strategies to enhance predation. The

325 substantial technological and social shifts observed in the Late Pleistocene archaeological record can be linked to shifts in population densities and foraging returns through their impacts on prey choices and abundances, settlement patterns, and foraging efficiency. They may also be detectable through off-site paleoenvironmental records such as charcoal and polycyclic aromatic hydrocarbons (in the case of fire), fungal or organic biomarker records (as proxies for herbivore biomass), or pollen and leaf wax data (as proxies for vegetation changes). with the introduction of novel, significant trophic elements into a system, sometimes called

333 'turnover' ${ }^{72}$. Trophic systems rely on relative stability of population dynamics, but when a new 334 species or selective pressure (in this case, a new human behavior or technology) is introduced, there can be radical reorganization. We view human use of fire to alter resource abundances and distributions as a threshold-crossing form of niche construction that rapidly alters the ecology of 337 fear. Within the context of savanna-forest mosaics, fire shifts the balance in favor of savanna ${ }^{73}$. 338 This alters herbivore abundances and distributions, which have further impact on vegetation 339 regimes that go beyond those incurred by the burning ${ }^{71}$. An ecology of fear promotes avoidance 340 of open land as landscapes revegetate following a fire, and this allows floral succession to 341 unfold; fire-tolerant savanna will eventually yield to fire-intolerant forest if burning does not 342 interrupt the process ${ }^{74}$. Thus, the impacts of human niche construction through burning or predation come from their immediate, conscious actions as well as from the downstream, 344 ripple effects of the ecology of fear. 
Environmental restructuring by humans opens novel predation opportunities for other predators ${ }^{75}$. In addition, our cooperative social behavior and extensive use of tools, including fire, has directly injected human intentionality into the lifecycles of plants and animals in a way that has amplified the capacity of humans to alter the latent ecology of fear. This amplification has led to tipping points in prehistory, beginning at least in the Pleistocene, in which there were temporal and spatial alterations in BMTCs that resulted from changes in the dimensions of an ecology of fear. Implicit in the BMTC model is that small disturbances can amplify through ecological systems, magnifying the scale of impacts. The introduction of new trophic dynamics into an ecological system undergoing extrinsically driven change (e.g., from climate change) has the potential to accelerate the race toward a tipping point ${ }^{76-78}$. Predictions drawn from BMTC theory show that indirect ecological impacts of fear-based systems can exceed direct impacts dependent on how fear is attenuated spatially, temporally, and according to ecological community structure ${ }^{79}$. In the case of the early human record, observed changes in one aspect of ecology can therefore be inferred to have impacts far beyond what might be preserved in the fossil or archaeological record.

\section{AN EARLY BMTC IN THE LATE PLEISTOCENE OF MALAWI}

A rare example of an explicit BMTC in the Late Pleistocene of Africa derives from northern Malawi, where both paleoenvironmental and archaeological data are available from the same region. Due to its long-axial position across the equator, the climate of the African continent is primarily governed by the north-south migration of the Intertropical Convergence Zone (ITCZ), which draws tropical, oceanic moisture inland and brings rain to the zone of maximum insolation (Fig. 2). Over multi-millennial timescales, changes in orbital configuration alter solar insolation and heat flux, which, in turn, change the meridional extent of the ITCZ. 
Zonal changes to atmospheric circulation are driven largely by sea surface temperature, which are dominated by dipole effects, such as the El Niño/Southern Oscillation or Indian Ocean Dipole ${ }^{80}$. Over the last $\sim 300 \mathrm{kyr}$, these effects combined with teleconnections to high-latitude changes in ice volume associated with three glacial-interglacial transitions have made significant changes in Earth's climate. These have affected the distribution of rainfall across Africa. Much of what is known about African paleoclimates comes from marine offshore or inland lacustrine drilling projects, which are temporally and spatially patchy ${ }^{81}$. Since at least the Pleistocene, there is a well-documented phenomenon of climatic antiphasing between the northern two-thirds and southern one-third of Africa, in which drier than modern conditions in one sector correlates with wetter than modern conditions in the other sector ${ }^{82}$. Central Africa thus experienced significant changes in climate that do not readily fit into either a broader northern or southern African regime. The longest continuous record of these changes from the continent itself is currently from the MAL05-1B lake sediment core from Lake Malawi, which offers a 1.3million-year sequence of hydrological and vegetation change ${ }^{83}$

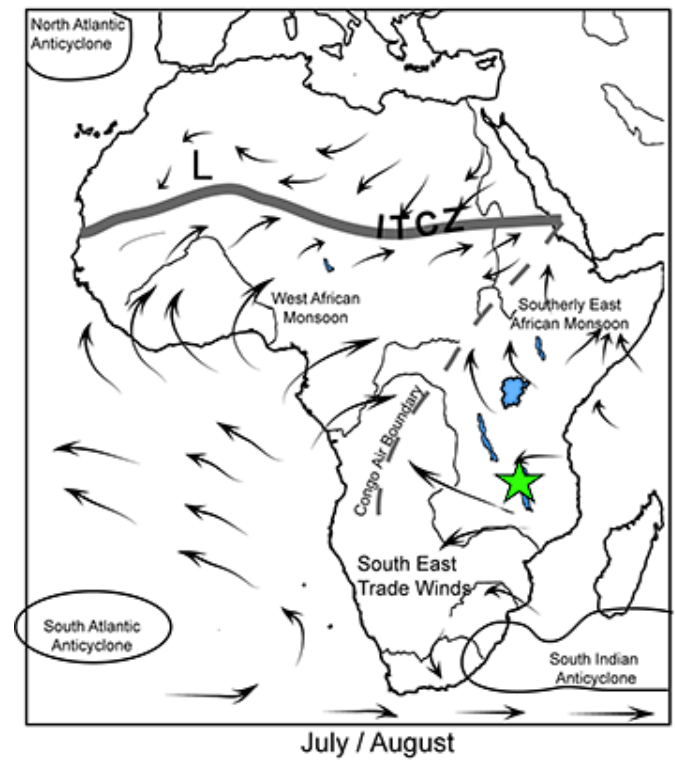

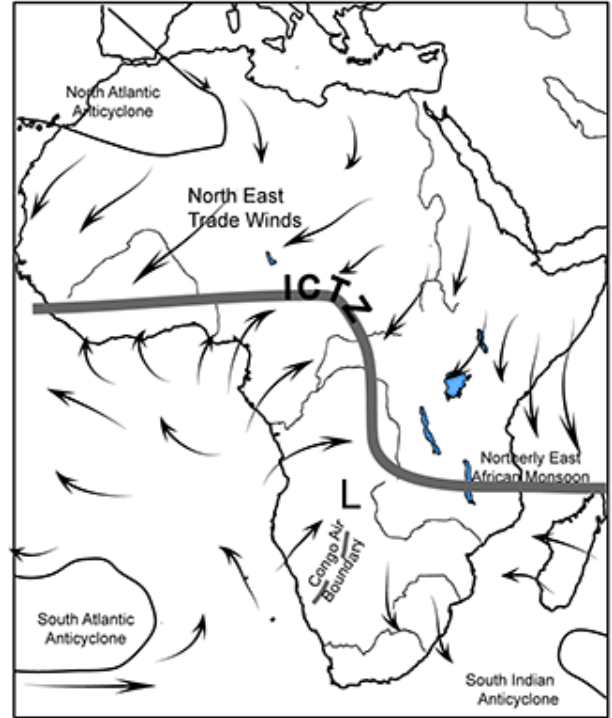

December
Figure 2. Map of Africa showing the major influences on climate (ITCZ, Congo Air Boundry, trade winds, monsoon direction), major water bodies (blue), and the location of the case study (green star). Adapted from Gasse ${ }^{102}$ 
The Pleistocene archaeological record for the region is predominately in the form of stone tools found entrained within alluvial fan systems to the east of Lake Malawi in Mozambique ${ }^{84}$ and to the northwest in the country of Malawi ${ }^{52}$. In both cases, age constraints indicate that the fan systems began forming in the Late Pleistocene and continued until the end of the epoch ${ }^{52,85-87}$. The tools themselves do not exhibit unusual complexity, but are largely assignable to technological systems attributed across Africa to the Middle Stone Age (MSA). MSA technology is known to have had its roots in the Middle Pleistocene ${ }^{48}$, with later additions of more complex elements in the Late Pleistocene ${ }^{53}$.

Data from the MAL05-1B core show several severe arid periods between 300-100 ka that would have resulted in a lake level decline of up to $95 \%^{88}$. These cycles corresponded to changes in vegetation as inferred from fossil pollen, in which forests expanded to the lakeshore during wet periods of high lake level and precipitation, and contracted in dry periods with decreasing lake level and precipitation ${ }^{89}$. Species richness as inferred from pollen also fluctuated with climate; during wet periods of forest expansion, species richness increased, and then decreased again during dry periods with falling lake levels ${ }^{90}$. However, ca. 85 ka, during a wet period following the last prolonged arid period, the long-term relationship between climate and vegetation was decoupled. Lake levels remained high for the last $85 \mathrm{kyr}$ but species richness never recovered, and instead remained at low values previously associated with the driest intervals of the last $600 \mathrm{kyr}$. All four previous low points were associated with a severe arid period, whereas the Late Pleistocene collapse occurred in concert with consistently high rainfall conditions. By ca. $85 \mathrm{ka}$, vegetation composition also changed to a previously unobserved state, in which montane forest taxa were largely replaced by grasses and fire-tolerant trees and shrubs 89. 
Analysis of the last $\sim 600 \mathrm{kyr}$ of this core shows important changes in fire activity indicated by charcoal that may explain alteration of vegetation complexion. Terrigenous charcoal occurred in core sediments at consistently low values until $\sim 250 \mathrm{ka}$, when it began to rise slightly. This was followed by two periods between $\sim 175-130 \mathrm{ka}$ and $\sim 100-85 \mathrm{ka}$ when charcoal influxes experienced high values more than double the long-term background value. The increase to higher than background levels of charcoal between $\sim 175-130$ ka was followed by an arid period that made vegetation likely too sparse to sustain fires. This suggests the introduction of a new fire regime into the overall system within the Middle Pleistocene, but with climate still governing the dominant patterns. During a major arid interval endingca. $85 \mathrm{ka}$. charcoal returned to high values as vegetation species richness dropped to some of its lowest levels over the last $\sim 600 \mathrm{kyr}^{91}$. After $85 \mathrm{ka}$, charcoal influx remained at higher baseline values than in preceding wet intervals.

These lines of evidence point to a series of recursive impacts, mediated by climate but ultimately following the introduction of widespread burning into the region, that drove a transition to a new vegetation state and a new ecological balance. Although people may have been present in the region during the Middle Pleistocene, their presence was not apparent in the archaeological record. The lake sediment core may instead offer the first indication of human occupation, with its changes in charcoal influxes after ca. 250 ka. Human activity is first manifested in the archaeological record between ca. $99-85 \mathrm{ka}$, based on the error range of the oldest date of both alluvial fan formation and archaeological occupation ${ }^{52}$. This occurred as lake levels began to recover and charcoal influx increase before ca. $85 \mathrm{ka}$. We argue that regional Late Pleistocene human populations began to grow as climate conditions became wetter, and this second series of charcoal maxima represent a simultaneous increase in human activity and fuel 
429 load as higher precipitation encouraged both woodland regrowth and human occupation. Unlike

430 their Middle Pleistocene counterparts, however, these humans used burning to halt the typical

431 cycle of forest recolonization by producing large quantities of ignitions that were outside the

432 normal seasonality of lightning strikes ${ }^{89,92}$.

433 Burning of vegetation by MSA people restructured the floristic composition of northern

434 Malawi during the Late Pleistocene, filtering out fire-intolerant species, reducing the overall

435 biodiversity of the landscape, but enhancing predation opportunities and stimulating resources

436 beneficial to themselves. This catalyzed a BMTC, which extended to the landscape itself, where

437 erosion regimes were altered by a novel combination of high precipitation and low forest cover.

438 It was at this time, in the Late Pleistocene, that regional alluvial fans began to activate and

439 entrain the first direct archaeological evidence of human presence (Fig. 3). A tipping point had

440 been reached, and a new vegetation and burning regime was established by ca. $72 \mathrm{ka}$. By the

441 time they became archaeologically visible, MSA hunter-gatherers had been using fire as a

442 resource management tool on those landscapes for thousands of years. Later farming and

443 pastoral activities then inherited a long ecological legacy sculpted by human niche construction

444 that began in the Pleistocene.

445 


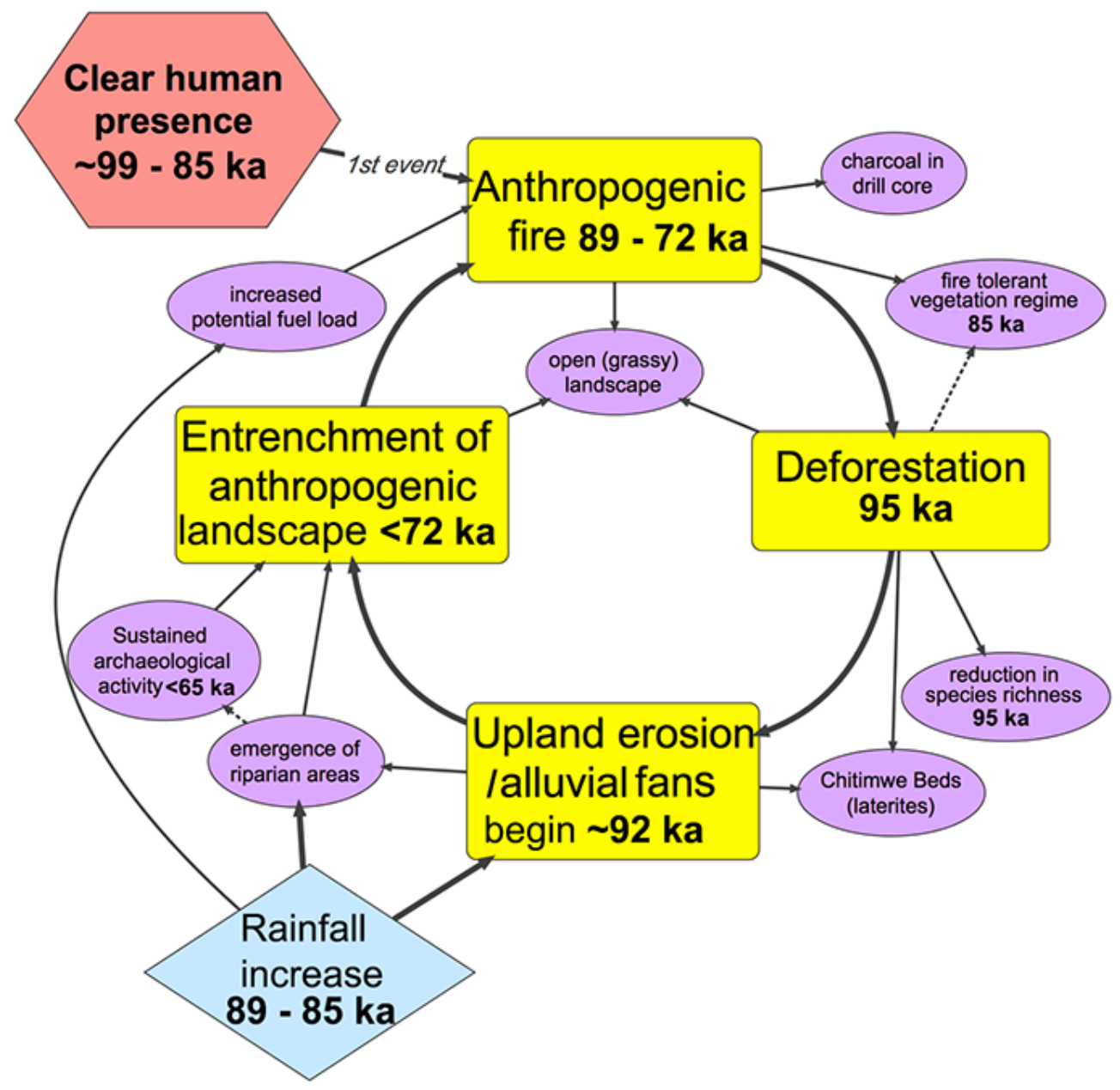

$447 \quad$ Figure 3. Conceptual path model of recursive interactions between forager cultural activities 448 and ecosystem expressions during the Late Pleistocene of northern Malawi. The introduction of anthropogenic burning between $\sim 99$ - 85 ka coincided with a recovery in lake levels after a major arid period, resulting in collapse of forests and expansion of fire-tolerant species. After 72 ka the system had crossed a permanent tipping point and entered a new balance in which open landscapes dominated even during sustained high rainfall conditions. Alluvial fans

453 catalyzed by these conditions continued to form. Yellow boxes indicate inferred effects of 454 anthrome creation. The blue diamond is the prime non-anthropogenic ecosystem driver. Purple 455 ovals are measured proxy data. Arrows temporally and conceptually connect events within the path model. 


\section{CONCLUSIONS}

The Paleoanthropocene concept confounds formal definition in the ecological or geological record because the evidence is not global, nor synchronous across large regions. Recent discussions about the Anthropocene include a call from anthropologists to be included in its formal definition ${ }^{9}$. However, in most ways the archaeological and paleoenvironmental records do not meet the criteria necessary for a typical geological transition; i.e. that there be a type section that represents a globally discernable and temporally constrained phenomenon ${ }^{93}$.

Ruddiman ${ }^{94}$ has proposed that an informal 'anthropocene' is conceptually preferable in its utility to a hard geological boundary. Indeed, from at least the Late Pleistocene, humans have induced many regional anthropocenes. The pragmatic problem is how to identify them, and the theoretical problem is how to frame their impacts on our evolution ${ }^{8}$. Scaling human impacts over geological timescales is difficult because separating the artificial from the natural aspects of selection is not always transparent. However, such separations are also not strictly necessary. Using indicators from artifactual and ecofactual assemblages, paleoenvironmental records, and explanations rooted in ecological co-evolutionary theory, early human niche construction can be traced to deeper points in time. In these cases, interpretation of records may seem reliant on an argument from circumstantial evidence: observable environmental change must coincide with observable anthropogenic activity. However, this may be a futile exercise when dealing with deep-time records where there are large temporal gaps between data points. Even over higher resolution spans, time lags should be expected as the norm rather than the exception, since ecological change across taxa should not all occur concurrently ${ }^{95}$. As ecosystems adjust to changing conditions, 
environmental components with different longevities (for example, grass versus trees) should not all show consistent impacts until a new balance is achieved.

Inferences about anthropogenic fire from charcoal records have been applied to regions where there is a clear 'before and after' presence of humans, such as the Americas ${ }^{96}$ and Australia ${ }^{97}$, but is more difficult to apply to Africa, where humans have had the longest presence 92. Because of this presence, however, Africa is the continent where we should predict that such behaviors first emerged and developed. We have proposed that a useful time to examine in the context of the African record is when archaeological evidence shows a clear change in human behaviors across the social, subsistence, and technological realms, around the Middle-to-Late Pleistocene boundary.

When paired with other paleoenvironmental proxies from the same cores such as pollen records, leaf waxes, and dung fungus (Sporormiella), charcoal from lake cores can speak to a complex set of interactions between fire and floral and faunal change. Interpretations from such proxies are unavoidably circumstantial, in that there is no definitive way to demonstrate that human behavior was the sole, or even primary, driver of regime change. However, modern hunter-gatherers are strongly predicted to use broadcast fire as a land management strategy in lightning-fire-prone environments as well as environments with few natural ignitions ${ }^{35,98}$. This demonstrates the fallacy of dichotomizing a lightning versus anthropogenic fire landscape, and instead emphasizes the evolving and contingent nature of fire regimes. Because of the ripple effect of BMTCs, evidence from paleoenvironmental proxies, even if the main connection to anthropogenic activity is circumstantial, is a prime source for identifying human niche construction. It also speaks directly to what makes humans unique. 


\section{Landscapes are inherited and amplified legacies of past evolutionary interactions,} and there is no disentanglement of the ecological present from the past. However, there is evidence that at some point near the Middle-Late Pleistocene boundary humans underwent a threshold-crossing shift in their behavior that is detectably different from what came before. The sustained, transformative effects of these behaviors on sculpting ecosystem functions extend deep into the human past and the evolution of these systems are inextricably bound to the evolution of our species itself 99 . The end result has been a ratcheting up in both cultural complexity ${ }^{100}$ and environmental changes ${ }^{101}$ to accommodate new ecological realities. This has set off cascades of further adaptations within our species and others in the same ecosystems at an unprecedented scale of impact.

\section{ACKNOWLEDGEMENTS}

We thank the organizers of the symposium "The Extended Evolutionary Synthesis and Human Origins: Archaeological Perspectives”, organized by John Murray and Robert Benitez at the $84^{\text {th }}$ annual Society for American Archaeology meeting in Albuquerque, New Mexico. We thank Grace Veatch and David Post for insightful conversation around the issue of niche construction theory, Steve Forman for discussion about the ecology of fear, and Erik Otárola-Castillo, Andy Cohen, and Ramón Arrowsmith for conversations around the path model. We also thank the Editor and two reviewers for their helpful comments and recommendations. 


\section{REFERENCES}

[1] Odling-Smee F, Laland K, Feldman M. Niche construction: the neglected process in evolution. Vol 37. Princeton: Princeton University Press; 2003.

[2] Laland KN, Odling-Smee J, Myles S. How culture shaped the human genome: Bringing genetics and the human sciences together. Nat Rev Genet. 2010;11(2):137-148.

[3] Sterelny K, Watkins T. Neolithization in Southwest Asia in a context of Niche Construction Theory. Cambridge Archaeological Journal. 2015;25(3):673-691.

[4] O'Brien MJ, Laland KN. Genes, culture, and agriculture: An example of human niche construction. Curr Anthropol. 2012;53(4):434-470.

[5] Whiten A, Ayala FJ, Feldman MW, Laland KN. The extension of biology through culture. Proc Natl Acad Sci. 2017;114(30):7775.

[6] Creanza N, Fogarty L, Feldman MW. Exploring cultural niche construction from the Paleolithic to modern hunter-gatherers. In: Akazawa T, Nishiaki Y, Aoki K, eds. Dynamics of Learning in Neanderthals and Modern Humans Volume 1: Cultural Perspectives. Tokyo: Springer Japan; 2013:211-228.

[7] Foley SF, Gronenborn D, Andreae MO, et al. The Palaeoanthropocene - The beginnings of anthropogenic environmental change. Anthropocene. 2013;3:83-88.

[8] Glikson A. Fire and human evolution: The deep-time blueprints of the Anthropocene. Anthropocene. 2013;3:89-92.

[9] Ellis E, Maslin M, Boivin N, Bauer A. Involve social scientists in defining the Anthropocene. Nature. 2016;540(7632):192-193.

[10] Faurby S, Silvestro D, Werdelin L, Antonelli A. Brain expansion in early hominins predicts carnivore extinctions in East Africa. Ecology Letters. 2020;23(3):537-544.

[11] Faith JT, Rowan J, Du A, Koch PL. Plio-Pleistocene decline of African megaherbivores: No evidence for ancient hominin impacts. Science. 2018;362(6417):938-941.

[12] Monjeau JA, Araujo B, Abramson G, Kuperman MN, Laguna MF, Lanata JL. The controversy space on Quaternary megafaunal extinctions. Quatern Int. 2017;431:194204.

[13] Albert RM. Anthropocene and early human behavior. The Holocene. 2015;25(10):15421552.

[14] Boivin NL, Zeder MA, Fuller DQ, et al. Ecological consequences of human niche construction: Examining long-term anthropogenic shaping of global species distributions. Proc Natl Acad Sci. 2016;113(23):6388-6396. 
[15] Post DM, Palkovacs EP. Eco-evolutionary feedbacks in community and ecosystem ecology: Interactions between the ecological theatre and the evolutionary play. Phil Trans $R$ Soc B. 2009;364(1523):1629-1640.

[16] Laland KN, Odling-Smee J, Feldman MW. Cultural niche construction and human evolution. Journal of Evolutionary Biology. 2001;14(1):22-33.

[17] Laland KN, O'Brien MJ. Niche construction theory and archaeology. J Arch Meth Theor. 2010;17(4):303-322.

[18] Hill K, Barton CM, Hurtado AM. The emergence of human uniqueness: Characters underlying behavioral modernity. Evol Anthrop. 2009;18:187-200.

[19] Migliano AB, Page AE, Gómez-Gardeñes J, et al. Characterization of hunter-gatherer networks and implications for cumulative culture. 2017;1:0043.

[20] Marean CW. The transition to foraging for dense and predictable resources and its impact on the evolution of modern humans. Philosophical Transactions of the Royal Society B. 2016;371(1698):20150239.

[21] Roberts P, Stewart BA. Defining the 'generalist specialist' niche for Pleistocene Homo sapiens. Nature Human Behaviour. 2018;2:542-550.

[22] Derex M, Boyd R. The foundations of the human cultural niche. Nature Communications. 2015;6(1):8398.

[23] Fuentes A. Integrative anthropology and the human niche: Toward a contemporary approach to human evolution. Am Anthrop. 2015;117(2):302-315.

[24] Richerson PJ, Boyd R, Henrich J. Gene-culture coevolution in the age of genomics. Proc Natl Acad Sci. 2010;107(Supplement 2):8985-8992.

[25] Laland KN, Odling-Smee J, Feldman MW. Niche construction, biological evolution, and cultural change. Behavioral and Brain Sciences. 2000;23(1):131-146.

[26] Kendal J, Tehrani JJ, Odling-Smee J. Human niche construction in interdisciplinary focus. Philosophical Transactions of the Royal Society B. 2011;366:785-792.

[27] Smith BD. Niche construction and the behavioral context of plant and animal domestication. Evol Anthrop. 2007;16(5):188-199.

[28] Bentley RA, O’Brien MJ. Modeling niche construction in Neolithic Europe. In: Saqalli M, Vander Linden M, eds. Integrating Qualitative and Social Science Factors in Archaeological Modelling. Cham: Springer International Publishing; 2019:91-108.

[29] Scheffer M, Carpenter SR. Catastrophic regime shifts in ecosystems: linking theory to observation. Trends in Ecology \& Evolution. 2003;18(12):648-656. 
[30] Power MJ, Codding BF, Taylor AH, et al. Human Fire Legacies on Ecological Landscapes. Frontiers in Earth Science. 2018;6(151).

[31] Turner BL, Kasperson RE, Meyer WB, et al. Two types of global environmental change: Definitional and spatial-scale issues in their human dimensions. Global Environmental Change. 1990;1(1):14-22.

[32] Biggs R, Boonstra W, Peterson G, Schlüter M. The domestication of fire as a socialecological regime shift. PAGES — Past Global Changes Magazine. 2016;24(1):22-23.

[33] Scherjon F, Bakels C, MacDonald K, Roebroeks W. Burning the land: An ethnographic study of off-site fire use by current and historically documented foragers and implications for the interpretation of past fire practices in the landscape. Curr Anthropol. 2015;56(3):299-326.

[34] Morgan C. Is it intensification yet? Current archaeological perspectives on the evolution of hunter-gatherer economies. Journal of Archaeological Research. 2015;23(2):163-213.

[35] Bliege Bird R, McGuire C, Bird DW, Price MH, Zeanah D, Nimmo DG. Fire mosaics and habitat choice in nomadic foragers. Proc Natl Acad Sci. 2020;117(23):12904-12914.

[36] Feeney J. Hunter-gatherer land management in the human break from ecological sustainability. The Anthropocene Review. 2019;6(3):223-242.

[37] Hamilton MJ, Milne BT, Walker RS, Brown JH. Nonlinear scaling of space use in human hunter-gatherers. Proc Natl Acad Sci. 2007;104(11):4765-4769.

[38] Ames KM. The Northwest Coast: Complex hunter-gatherers, ecology, and social evolution. Annual Review of Anthropology. 1994;23(1):209-229.

[39] Lupo KD, Schmitt DN. Upper Paleolithic net-hunting, small prey exploitation, and women's work effort: a view from the ethnographic and ethnoarchaeological record of the Congo basin. J Arch Meth Theor. 2002;9(2):147-179.

[40] Holly J, Donald H. The place of "others" in hunter-gatherer intensification. Am Anthrop. 2005;107(2):207-220.

[41] Smith BD. General patterns of niche construction and the management of 'wild' plant and animal resources by small-scale pre-industrial societies. Phil Trans $R$ Soc B. 2011;366(1566):836-848.

[42] O'Shea JM, Lemke AK, Sonnenburg EP, Reynolds RG, Abbott BD. A 9,000-year-old caribou hunting structure beneath Lake Huron. Proc Natl Acad Sci. 2014;111(19):69116915.

[43] Parker CH, Keefe ER, Herzog NM, O'connell JF, Hawkes K. The pyrophilic primate hypothesis. Evol Anthrop. 2016;25(2):54-63. 
[44] Bliege Bird R, Bird DW, Codding BF, Parker CH, Jones JH. The "fire stick farming" hypothesis: Australian Aboriginal foraging strategies, biodiversity, and anthropogenic fire mosaics. Proc Natl Acad Sci. 2008;105(39):14796-14801.

[45] Bird DW, Bird RB, Codding BF, Zeanah DW. Variability in the organization and size of hunter-gatherer groups: Foragers do not live in small-scale societies. J Hum Evol. 2019;131:96-108.

[46] Stout D, Hecht EE. Evolutionary neuroscience of cumulative culture. Proc Natl Acad Sci. 2017;114(30):7861-7868.

[47] McBrearty S, Brooks AS. The revolution that wasn't: A new interpretation of the origin of modern human behavior. J Hum Evol. 2000;39:453-563.

[48] Blegen N, Jicha BR, McBrearty S. A new tephrochronology for early diverse stone tool technologies and long-distance raw material transport in the Middle to Late Pleistocene Kapthurin Formation, East Africa. J Hum Evol. 2018;121:75-103.

[49] Brooks AS, Yellen JE, Potts R, et al. Long-distance stone transport and pigment use in the earliest Middle Stone Age. Science. 2018;360(6384):90-94.

[50] O'Driscoll CA, Thompson JC. The origins and early elaboration of projectile technology. Evol Anthrop. 2018;27(1):30-45.

[51] Richter D, Grün R, Joannes-Boyau R, et al. The age of the hominin fossils from Jebel Irhoud, Morocco, and the origins of the Middle Stone Age. Nature. 2017;546(7657):293296.

[52] Thompson JC, Mackay A, Nightingale S, et al. Ecological risk, demography and technological complexity in the Late Pleistocene of northern Malawi: implications for geographical patterning in the Middle Stone Age. Journal of Quaternary Science. 2018;33(3):261-284.

[53] Wadley L. Those marvellous millennia: the Middle Stone Age of Southern Africa. Azania: Archaeological Research in Africa. 2015;50(2):155-226.

[54] Tryon CA, Faith JT. Variability in the Middle Stone Age of eastern Africa. Curr Anthropol. 2013;54(S8):S234-S254.

[55] Yellen JE. Barbed bone points: tradition and continuity in Saharan and sub-Saharan Africa. African Archaeological Review. 1998;15:173-198.

[56] Esteban I, Marean CW, Fisher EC, Karkanas P, Cabanes D, Albert RM. Phytoliths as an indicator of early modern humans plant gathering strategies, fire fuel and site occupation intensity during the Middle Stone Age at Pinnacle Point 5-6 (south coast, South Africa). PLOS ONE. 2018;13(6):e0198558. 
[57] d'Errico F, Banks WE, Warren DL, et al. Identifying early modern human ecological niche expansions and associated cultural dynamics in the South African Middle Stone Age. Proc Natl Acad Sci. 2017;114(30):7869-7876.

[58] Jones MB, Brandt SA, Marshall F. Hunter-gatherer reliance on inselbergs, big game, and dwarf antelope at the Rifle Range Site, Buur Hakaba, southern Somalia 20,000- 5,000 BP. Quatern Int. 2018;471:55-65.

[59] Di Lernia S. The emergence and spread of herding in northern Africa: a critical reappraisal. In: Mitchell P, Lane P, eds. The Oxford Handbook of African Archaeology. Oxford: Oxford University Press; 2013:527-540.

[60] Zerboni A, Nicoll K. Enhanced zoogeomorphological processes in North Africa in the human-impacted landscapes of the Anthropocene. Geomorphology. 2018.

[61] Mulazzani S, Belhouchet L, Salanova L, et al. The emergence of the Neolithic in North Africa: A new model for the Eastern Maghreb. Quatern Int. 2016;410:123-143.

[62] Prendergast ME, Beyin A. Fishing in a fluctuating landscape: terminal Pleistocene and early Holocene subsistence strategies in the Lake Turkana Basin, Kenya. Quatern Int. 2018;471:203-218.

[63] Zeder MA. Reply to Mohlenhoff et al.: Human behavioral ecology needs a rethink that niche-construction theory can provide. Proc Natl Acad Sci. 2015;112(24):E3094.

[64] Mohlenhoff KA, Coltrain JB, Codding BF. Optimal foraging theory and nicheconstruction theory do not stand in opposition. Proc Natl Acad Sci. 2015;112(24):E3093E3093.

[65] Henrich J, McElreath R. Dual-inheritance theory: The evolution of human cultural capacities and cultural evolution. In: Barrett L, Dunbar R, Henrich J, McElreath R, eds. Vol 38. Oxford: Oxford University Press; 2007:555-570.

[66] Kraaij T, Engelbrecht F, Franklin J, Cowling RM. A fiery past: A comparison of glacial and contemporary fire regimes on the Palaeo-Agulhas Plain, Cape Floristic Region. Quaternary Science Reviews. 2020;235:106059.

[67] Brown JS, Kotler BP. Hazardous duty pay and the foraging cost of predation. Ecology Letters. 2004;7(10):999-1014.

[68] Brown JS, Laundré JW, Gurung M. The Ecology of Fear: Optimal foraging, game theory, and trophic interactions. Journal of Mammalogy. 1999;80(2):385-399.

[69] Rosenzweig ML, MacArthur RH. Graphical representation and stability conditions of predator-prey interactions. The American Naturalist. 1963;97(895):209-223. 
[70] le Roux E, Kerley GIH, Cromsigt JPGM. Megaherbivores modify trophic cascades triggered by fear of predation in an African savanna ecosystem. Current Biology. 2018;28(15):2493-2499.e2493.

[71] Cherry MJ, Warren RJ, Mike Conner L. Fear, fire, and behaviorally mediated trophic cascades in a frequently burned savanna. Forest Ecology and Management. 2016;368:133-139.

[72] Turner MG, Gardner RH. Organisms and landscape pattern. In: Turner MG, Gardner RH, eds. Landscape Ecology in Theory and Practice: Pattern and Process. New York, New York: Springer; 2015:229-285.

[73] Hély C, Alleaume S, Runyan CW. Fire Regimes in Dryland Landscapes. In: D'Odorico P, Porporato A, Wilkinson Runyan C, eds. Dryland Ecohydrology. Cham: Springer International Publishing; 2019:367-399.

[74] Hoffmann WA, Geiger EL, Gotsch SG, et al. Ecological thresholds at the savanna-forest boundary: How plant traits, resources and fire govern the distribution of tropical biomes. Ecology Letters. 2012;15(7):759-768.

[75] Fleming PA, Bateman PW. Novel predation opportunities in anthropogenic landscapes. Animal Behaviour. 2018;138:145-155.

[76] Folke C, Carpenter S, Walker B, et al. Regime shifts, resilience, and biodiversity in ecosystem management. Annual Review of Ecology, Evolution, and Systematics. 2004;35:557-581.

[77] Kinzig AP, Ryan PA, Etienne M, Allison HE, Elmqvist T, Walker BH. Resilience and regime shifts: Assessing cascading effects. Ecology and Society. 2006;11(1):20.

[78] Andersen T, Carstensen J, Hernández-García E, Duarte CM. Ecological thresholds and regime shifts: Approaches to identification. Trends in Ecology \& Evolution. 2009;24(1):49-57.

[79] Schmitz OJ, Krivan V, Ovadia O. Trophic cascades: The primacy of trait-mediated indirect interactions. Ecology Letters. 2004;7(2):153-163.

[80] deMenocal PB. African climate change and faunal evolution during the PliocenePleistocene. Earth and Planetary Science Letters. 2004;220(1):3-24.

[81] Cohen A, Campisano C, Arrowsmith R, et al. The Hominin Sites and Paleolakes Drilling Project: Inferring the environmental context of human evolution from eastern African rift lake deposits. Sci Dril. 2016;21:1-16.

[82] Partridge T, Demenocal P, Lorentz S, Paiker M, Vogel J. Orbital forcing of climate over South Africa: A 200,000-year rainfall record from the Pretoria Saltpan. Quaternary Science Reviews. 1997;16(10):1125-1133. 
[83] Lyons RP, Scholz CA, Cohen AS, et al. Continuous 1.3-million-year record of East African hydroclimate, and implications for patterns of evolution and biodiversity. Proc Natl Acad Sci. 2015;112(51):15568-15573.

[84] Mercader J, Gosse JC, Bennett T, Hidy AJ, Rood DH. Cosmogenic nuclide age constraints on Middle Stone Age lithics from Niassa, Mozambique. Quaternary Science Reviews. 2012;47:116-130.

[85] Wright DK, Thompson J, Mackay A, et al. Renewed geoarchaeological investigations of Mwanganda's Village (Elephant Butchery Site), Karonga, Malawi. Geoarchaeology. 2014;29(2):98-120.

[86] Wright DK, Thompson JC, Schilt F, et al. Approaches to Middle Stone Age landscape archaeology in tropical Africa. J Archaeol Sci. 2017;77:64-77.

[87] Nightingale S, Schilt F, Thompson JC, et al. Late Middle Stone Age Behavior and Environments at Chaminade I (Karonga, Malawi). Journal of Paleolithic Archaeology. 2019;2(3):258-297.

[88] Scholz CA, Johnson TC, Cohen AS, et al. East African megadroughts between 135 and 75 thousand years ago and bearing on early-modern human origins. Proceedings of the National Academy of Science. 2007;104:16416-16421.

[89] Ivory SJ, Lézine A-M, Vincens A, Cohen AS. Waxing and waning of forests: Late Quaternary biogeography of southeast Africa. Global Change Biology. 2018;24(7):29392951.

[90] Bowman DMJS, Perry GLW, Higgins SI, Johnson CN, Fuhlendorf SD, Murphy BP. Pyrodiversity is the coupling of biodiversity and fire regimes in food webs. Philosophical transactions of the Royal Society of London Series B, Biological sciences. 2016;371(1696):20150169.

[91] Ivory SJ, Lézine AM, Vincens A, Cohen A, S. Waxing and waning of forests: Late Quaternary biogeography of southeast Africa. Global Change Biology. 2018;24(7):29392951.

[92] Archibald S, Staver AC, Levin SA. Evolution of human-driven fire regimes in Africa. Proc Natl Acad Sci. 2012;109(3):847-852.

[93] Lewis SL, Maslin MA. Defining the Anthropocene. Nature. 2015;519:171.

[94] Ruddiman WF. Three flaws in defining a formal 'Anthropocene'. Progress in Physical Geography: Earth and Environment. 2018;42(4):451-461.

[95] Williams JW, Post DM, Cwynar LC, Lotter AF, Levesque AJ. Rapid and widespread vegetation responses to past climate change in the North Atlantic region. Geology. 2002;30(11):971-974. 
759

760

761

762

763

764

765

766

767

768

769

770

771

772

773

774

775

[96] Gill JL, Williams JW, Jackson ST, Lininger KB, Robinson GS. Pleistocene megafaunal collapse, novel plant communities, and enhanced fire regimes in North America. Science. 2009;326(5956):1100-1103.

[97] Rule S, Brook BW, Haberle SG, Turney CS, Kershaw AP, Johnson CN. The aftermath of megafaunal extinction: Ecosystem transformation in Pleistocene Australia. Science. 2012;335(6075):1483-1486.

[98] Coughlan MR, Magi BI, Derr KM. A global analysis of hunter-gatherers, broadcast fire use, and lightning-fire-prone landscapes. Fire. 2018;1(3):41.

[99] Ellis EC. Ecology in an anthropogenic biosphere. Ecological Monographs. 2015;85(3):287-331.

[100] Tennie C, Call J, Tomasello M. Ratcheting up the ratchet: On the evolution of cumulative culture. Phil Trans R Soc B. 2009;364(1528):2405-2415.

[101] Sullivan AP, Bird DW, Perry GH. Human behaviour as a long-term ecological driver of non-human evolution. Nature Ecology \& Evolution. 2017;1:0065.

[102] Gasse F. Hydrological changes in the African tropics since the Last Glacial Maximum. Quaternary Science Reviews. 2000;19(1-5):189-211. 